\title{
Anti-fuzzy KUS-ideals of KUS-algebras
}

\author{
Samy M. Mostafa \\ Department of Mathematics, \\ Faculty of Education, \\ Ain Shams University, Cairo, Egypt.
}

\author{
Areej T. Hameed \\ Department of Mathematics, \\ College of Education for Girls, \\ University of Kufa, Najaf, Iraq.
}

\begin{abstract}
In this paper, we introduce the notion of anti-fuzzy KUSideals in KUS-algebra, several appropriate examples are provided and their some properties are investigated. The image and the inverse image of anti-fuzzy KUS-ideals in KUS-algebra are defined and how the image and the inverse image of anti-fuzzy KUS-ideals in KUS-algebra become antifuzzy KUS-ideals are studied. Moreover, the cartesian product of anti-fuzzy KUS-ideals are given .
\end{abstract}

\section{Keywords}

KUS-ideals , fuzzy KUS-ideals , anti-fuzzy KUS-ideals , image and pre-image of anti-fuzzy KUS-ideals.

\section{INTRODUCTION}

After the introduction of fuzzy subsets by L.A. Zadeh [10], several researchers explored on the generalization of the notion of fuzzy subset. H.V. Kumbhojkar and M.S. Bapat [4] defined not-so-fuzzy fuzzy ideals, N. Palaniappan and K. Arjunan [7] defined the anti-homomorphism of a fuzzy and an anti-fuzzy ideals.BCK - algebras form an important class of logical algebras introduced by $\mathrm{K}$. Iseki [2] and was extensively investigated by several researchers. The class of all BCK-algebras is quasi variety. Y. B. Jun, J. Meng and et al posed an interesting problem (solved in ([3], [5])) whether the class of all BCK-algebras is a variety. In ([8],[9]), C. Prabpayak and U. Leerawat introduced a new algebraic structure, which is called KU-algebra . They gave the concept of homomorphisms of KU-algebras and investigated some related properties. S. Mostafa, and et al (in [6]) introduced the notion of fuzzy KUS-ideals of KUS-algebras and they investigated several basic properties which are related to fuzzy KUS-ideals. they described how to deal with the homomorphism image and inverse image of fuzzy KUSideals. they have also proved that the cartesian product of fuzzy KUS-ideals in cartesian product of fuzzy KUS-algebras are fuzzy KUS-ideals. In this paper, we introduce the notion of anti-fuzzy KUS-ideals of KUS-algebras and then we study the homomorphism image and inverse image of anti-fuzzy KUS-ideals. We also prove that the cartesian product of antifuzzy KUS-ideals is an anti-fuzzy KUS-ideals .

\section{Preliminaries}

In this section we give some basic definitions and preliminaries lemmas of KUS-ideals and fuzzy KUS-ideals of KUS-algebras .

Definition 2.1([6]). Let $(\mathrm{X} ; *, 0)$ be an algebra with a single binary operation $(*)$. $\mathrm{X}$ is called a KUS-algebra if it satisfies the following identities: for any $\mathrm{x}, \mathrm{y}, \mathrm{z} \in \mathrm{X}$,

$\left(\mathrm{kus}_{1}\right):(\mathrm{z} * \mathrm{y}) *(\mathrm{z} * \mathrm{x})=\mathrm{y} * \mathrm{x}$

$\left(\mathrm{kus}_{2}\right): 0 * \mathrm{x}=\mathrm{x}$,

$\left(\mathrm{kus}_{3}\right): \mathrm{x} * \mathrm{x}=0$ $\left(\mathrm{kus}_{4}\right): \mathrm{x} *(\mathrm{y} * \mathrm{z})=\mathrm{y} *(\mathrm{x} * \mathrm{z})$.

In what follows, let $(\mathrm{X} ; *, 0)$ denote a KUS-algebra unless otherwise specified.

For brevity we also call X a KUS-algebra. In X we can define a binary relation $(\leq)$

by : $\mathrm{x} \leq \mathrm{y}$ if and only if $\mathrm{y} * \mathrm{x}=0$.

Lemma 2.2 ([6]). In any KUS-algebra $(X ; *, 0)$, the following properties holds: for all $\mathrm{x}, \mathrm{y}, \mathrm{z} \in \mathrm{X}$;

a) $\mathrm{x} * \mathrm{y}=0$ and $\mathrm{y} * \mathrm{x}=0$ imply $\mathrm{x}=\mathrm{y}$,

b) $\mathrm{y} *[(\mathrm{y} * \mathrm{z}) * \mathrm{z}]=0$

c) $(0 * \mathrm{x}) *(\mathrm{y} * \mathrm{x})=\mathrm{y} * 0$,

d) $\mathrm{x} \leq \mathrm{y}$ implies that $\mathrm{y} * \mathrm{z} \leq \mathrm{x} * \mathrm{z}$ and

$$
\mathrm{z} * \mathrm{x} \leq \mathrm{z} * \mathrm{y}
$$

e) $\mathrm{x} \leq \mathrm{y}$ and $\mathrm{y} \leq \mathrm{z}$ imply $\mathrm{x} \leq \mathrm{z}$,

f) $\mathrm{x} * \mathrm{y} \leq \mathrm{z}$ implies that $\mathrm{z} * \mathrm{y} \leq \mathrm{x}$.

Definition 2.3 ([6]). A nonempty subset $\mathrm{S}$ of a KUS-algebra $\mathrm{X}$ is called a KUS-sub-algebra of $\mathrm{X}$ if $\mathrm{x} * \mathrm{y} \in \mathrm{S}$, whenever $\mathrm{x}$ ,$y \in S$.

Definition 2.4 ([6]). A nonempty subset I of a KUS-algebra $X$ is called a KUS-ideal of $X$ if it satisfies: for $x, y, z \in X$, $\left(\right.$ Ikus $\left._{1}\right) \quad(0 \in \mathrm{I})$,

$\left(\operatorname{Ikus}_{2}\right) \quad(\mathrm{z} * \mathrm{y}) \in \mathrm{I}$ and $(\mathrm{y} * \mathrm{x}) \in \mathrm{I}$ imply $(\mathrm{z} * \mathrm{x}) \in \mathrm{I}$.

Definition 2.5 ([9]). Let $(\mathrm{X} ; *, 0)$ and $\left(\mathrm{Y}^{*} *^{\prime}, 0^{\prime}\right)$ be nonempty sets. The mapping

$f:(\mathrm{X} ; *, 0) \rightarrow\left(\mathrm{Y} ; *^{*}{ }^{`}, 0^{`}\right)$ be called a homomorphism if it satisfying

$f(\mathrm{x} * \mathrm{y})=f(\mathrm{x}) * \backslash f(\mathrm{y})$ for all $\mathrm{x}, \mathrm{y} \in \mathrm{X}$. The set

$\left\{\mathrm{x} \in \mathrm{X} \mid f(\mathrm{x})=0^{\prime}\right\}$ is called the Kernel of $f$ denoted by Ker $f$.

Definition 2.6([10]). Let $(\mathrm{X} ; *, 0)$ be a nonempty set, a fuzzy subset $\mu$ in $X$ is a function $\mu: \mathrm{X} \rightarrow[0,1]$.

Definition 2.7([6]). Let $(X ; *, 0)$ be a KUS-algebra , a fuzzy subset $\mu$ in $X$ is called a fuzzy KUS-sub-algebra of $X$ if for all $\mathrm{x}, \mathrm{y} \in \mathrm{X}$,

$\mu(\mathrm{x} * \mathrm{y}) \geq \min \{\mu(\mathrm{x}), \mu(\mathrm{y})\}$.

Definition 2.8([6]). Let $(X ; *, 0)$ be a KUS-algebra , a fuzzy subset $\mu$ in $X$ is called a fuzzy KUS-ideal of $X$ if it satisfies the following conditions: , for all $\mathrm{x}, \mathrm{y}, \mathrm{z} \in \mathrm{X}$, (Fkus 1$) \quad \mu(0) \geq \mu(\mathrm{x})$,

$\left(\right.$ Fkus $\left._{2}\right) \quad \mu(\mathrm{z} * \mathrm{x}) \geq \min \{\mu(\mathrm{z} * \mathrm{y}), \mu(\mathrm{y} * \mathrm{x})\}$.

\section{Anti-fuzzy KUS-ideals of}




\section{KUS-algebras}

In this section, we will introduce a new notion called an anti-fuzzy KUS-ideal of KUS-algebra and study several basic properties of it.

Definition 3.1. Let $(\mathrm{X} ; *, 0)$ be a KUS-algebra. A fuzzy set $\mu$ in $X$ is called an anti-fuzzy KUS-ideal of $X$ if it satisfies the following conditions: for all $\mathrm{x}, \mathrm{y}$ and $\mathrm{z} \in \mathrm{X}$, $\left(\right.$ Akus $\left._{1}\right) \quad \mu(0) \leq \mu(\mathrm{x})$.

$\left(\right.$ Akus $\left._{2}\right) \quad \mu(\mathrm{z} * \mathrm{x}) \leq \max \{\mu(\mathrm{z} * \mathrm{y}), \mu(\mathrm{y} * \mathrm{x})\}$.

Example 3.2. Let $X=\{0,1,2,3\}$ in which $(*)$ is defined by the following table:

\begin{tabular}{|c|c|c|c|c|}
\hline$*$ & 0 & 1 & 2 & 3 \\
\hline 0 & 0 & 1 & 2 & 3 \\
\hline 1 & 3 & 0 & 1 & 2 \\
\hline 2 & 2 & 3 & 0 & 1 \\
\hline 3 & 1 & 2 & 3 & 0 \\
\hline
\end{tabular}

Then $(\mathrm{X} ; *, 0)$ is a KUS-algebra. Define a fuzzy set $\mu: \mathrm{X} \rightarrow$ $[0,1]$ by $\mu(0)=\mathrm{t}_{1}$,

$\mu(1)=\mu(2)=\mu(3)=t_{2}$, where $t_{1}, t_{2} \in[0,1]$ with $t_{1}<t_{2}$. Routine calculation gives that $\mu$ is an anti-fuzzy KUS-ideal of KUS-algebras X.

Lemma 3.3. Let $\mu$ be an anti-fuzzy KUS-ideal of KUSalgebra $X$ and if $x \leq y$, then $\mu(x) \leq \mu(y)$, for all $x, y \in X$. Proof: Assume that $\mathrm{x} \leq \mathrm{y}$, then $\mathrm{y} * \mathrm{x}=0$, and $\mu(0 * \mathrm{x})=\mu(\mathrm{x}) \leq \max \{\mu(0 * \mathrm{y}), \mu(\mathrm{y} * \mathrm{x})\}$ $=\max \{\mu(\mathrm{y}), \mu(0)\}=\mu(\mathrm{y})$. Hence $\mu(\mathrm{x}) \leq \mu(\mathrm{y})$. $\Delta$

Proposition 3.4. Let $\mu$ be an anti-fuzzy KUS-ideal of KUSalgebra $\mathrm{X}$. If the inequality $\mathrm{y} * \mathrm{x} \leq \mathrm{z}$ hold in $\mathrm{X}$, then $\mu(\mathrm{x})$ $\leq \max \{\mu(\mathrm{y}), \mu(\mathrm{z})\}$

Proof: Assume that the inequality $\mathrm{y} * \mathrm{x} \leq \mathrm{z}$ hold in $\mathrm{X}$, by lemma (3.3), $\quad \mu(\mathrm{y} * \mathrm{x}) \leq \mu(\mathrm{z})--(1)$.

By(Akus $), \mu(\mathrm{z} * \mathrm{x}) \leq \max \{\mu(\mathrm{z} * \mathrm{y}), \mu(\mathrm{y} * \mathrm{x})\}$. Put $\mathrm{z}=0$, then

$\mu(0 * \mathrm{x})=\mu(\mathrm{x}) \leq \max \{\mu(0 * \mathrm{y}), \mu(\mathrm{y} * \mathrm{x})\}$

$=\max \{\mu(\mathrm{y}), \mu(\mathrm{y} * \mathrm{x})\}---(2)$.

From (1) and (2), we get $\mu(x) \leq \max \{\mu(y), \mu(z)\}$, for all $x, y$, $\mathrm{z} \in \mathrm{X}$. $\Delta$

Theorem 3.5. Let $\mu$ be an anti-fuzzy set in $X$ then $\mu$ is an anti-fuzzy KUS-ideal of $\mathrm{X}$ if and only if it satisfies: if $\mathrm{U}(\mu, \alpha)=\{\mathrm{x} \in \mathrm{X} \mid \mu(\mathrm{x}) \leq \alpha\}$, for all $\alpha \in[0,1], \quad U(\mu, \alpha) \neq \varnothing$ implies $U(\mu, \alpha)$ is a KUS-ideal of X--- (A) .

Proof: Assume that $\mu$ is an anti-fuzzy KUS-ideal of $X$, let $\alpha \in[0,1]$ be such that $U(\mu, \alpha) \neq \varnothing$, and let $x, y \in X$ be such that $\mathrm{x} \in \mathrm{U}(\mu, \alpha)$, then $\mu(\mathrm{x}) \leq \alpha$ and so by $\left(\right.$ Akus $\left._{1}\right), \mu(0) \leq$ $\mu(\mathrm{x}) \leq \alpha$. Thus

$0 \in \mathrm{U}(\mu, \alpha)$.

Now let $(\mathrm{z} * \mathrm{y}),(\mathrm{y} * \mathrm{x}) \in \mathrm{U}(\mu, \alpha)$. It follows from $\left(\mathrm{Akus}_{2}\right)$ that

$\mu(\mathrm{z} * \mathrm{x}) \leq \max \{\mu(\mathrm{z} * \mathrm{y}), \mu(\mathrm{y} * \mathrm{x})\}=\alpha$, so that $(\mathrm{z} * \mathrm{x})$

$\in \mathrm{U}(\mu, \alpha)$. Hence $\mathrm{U}(\mu, \alpha)$ is a KUS-ideal of $\mathrm{X}$.

Conversely, suppose that $\mu$ satisfies (A), assume that $\left(\mathrm{Akus}_{1}\right)$ is false, then there exist $\mathrm{x} \in \mathrm{X}$ such that $\mu(0)>\mu(\mathrm{x})$. If we take

$\mathrm{t}=\frac{1}{2}[\mu(\mathrm{x})+\mu(0)]$, then $\mu(0)>\mathrm{t}$ and

2

$0 \leq \mu(\mathrm{x})<\mathrm{t} \leq 1$, thus $\mathrm{x} \in \mathrm{U}(\mu, \mathrm{t})$ and

$\mathrm{U}(\mu, \mathrm{t}) \neq \varnothing$. As $\mathrm{U}(\mu, \mathrm{t})$ is a KUS-ideal of $\mathrm{X}$, we have $0 \in$

$\mathrm{U}(\mu, \mathrm{t})$, and so $\mu(0) \leq \mathrm{t}$. This is a contradiction. Hence $\mu$

$(0) \leq \mu(\mathrm{x})$ for all $\mathrm{x} \in \mathrm{X}$. Now, assume $\left(\mathrm{Akus}_{2}\right)$ is not true then there exist

$\mathrm{x}, \mathrm{y}, \mathrm{z} \in \mathrm{X}$ such that

$\mu(\mathrm{z} * \mathrm{x})>\max \{\mu(\mathrm{z} * \mathrm{y}), \mu(\mathrm{y} * \mathrm{x})\}$,

taking $\beta_{0}=\frac{1}{2}[\mu(\mathrm{z} * \mathrm{x})+\max \{\mu(\mathrm{z} * \mathrm{y}), \mu(\mathrm{y} * \mathrm{x})\}]$, we have

$\beta_{0} \in[0,1]$ and

$\max \{\mu(\mathrm{z} * \mathrm{y}), \mu(\mathrm{y} * \mathrm{x})\}<\beta_{0}<\mu(\mathrm{z} * \mathrm{x})$, it follows that $\max \{\mu(\mathrm{z} * \mathrm{y}), \mu(\mathrm{y} * \mathrm{x})\} \in \mathrm{U}\left(\mu, \beta_{0}\right)$ and

$\mathrm{z} * \mathrm{x} \notin \mathrm{U}\left(\mu, \beta_{0}\right)$, this is a contradiction and therefore $\mu$ is an anti-fuzzy KUS-ideal of $X$. $\bullet$

\section{Characterization of anti-fuzzy KUS- ideals by their level KUS-ideals}

Theorem 4.1. A fuzzy subset $\mu$ of a KUS-algebra $X$ is an anti-fuzzy KUS-ideal of $X$ if and only if, for every $t \in[0,1]$,

$\mu_{t}$ is either empty or a KUS-ideal of X, where $\mu_{t}=\{x \in X$ $\mid \mu(\mathrm{x}) \leq \mathrm{t}\}$.

Proof: Assume that $\mu$ is an anti-fuzzy KUS-ideal of X, by (Akus $_{1}$ ), we have $\mu(0) \leq \mu(\mathrm{x})$ for all $\mathrm{x} \in \mathrm{X}$, therefore $\mu(0) \leq$ $\mu(\mathrm{x}) \leq \mathrm{t}$, for $\mathrm{x} \in \mu_{\mathrm{t}}$ and so

$0 \in \mu_{\mathrm{t}}$.

Let $(\mathrm{z} * \mathrm{y}) \in \mu_{\mathrm{t}}$ and $(\mathrm{y} * \mathrm{x}) \in \mu_{\mathrm{t}}$, then

$\mu\left(\mathrm{z}^{*} \mathrm{y}\right) \leq \mathrm{t}$ and $\mu(\mathrm{y} * \mathrm{x}) \leq \mathrm{t}$, since $\mu$ is an anti-fuzzy KUSideal it follows that

$\mu(\mathrm{z} * \mathrm{x}) \leq \max \{\mu(\mathrm{z} * \mathrm{y}), \mu(\mathrm{y} * \mathrm{x})\} \leq \mathrm{t}$ and that $(\mathrm{z} * \mathrm{x}) \in$ $\mu_{t}$. Hence $\mu_{t}$ is a KUS-ideal of $X$.

Conversely, we only need to show that (Akus 1 ) and $\left(\right.$ Akus $\left._{2}\right)$ are true. If $\left(\right.$ Akus $\left._{1}\right)$ is false, then there exist $\mathrm{x} \in \mathrm{X}$ such that $\mu(0)>\mu(\mathrm{x})$. If we take $\mathrm{t}=\frac{1}{2}(\mu(\mathrm{x})+\mu(0))$, then $\mu(0)>\mathrm{t}$ and

$0 \leq \mu(\mathrm{x})<\mathrm{t} \leq 1$ thus $\mathrm{x} \in \mu_{\mathrm{t}}$ and $\mu_{\mathrm{t}} \neq \varnothing$. As $\mu_{\mathrm{t}}$ is a

KUS-ideal of $X$, we have $0 \in \mu_{t}$ and so $\mu(0) \leq t$. This is a contradiction.

Now, assume $\left(\mathrm{Akus}_{2}\right)$ is not true, then there exist $\mathrm{x}, \mathrm{y}$ and $\mathrm{z} \in \mathrm{X}$ such that,

$\mu\left(\mathrm{z}^{*} \mathrm{x}\right)>\max \left\{\mu\left(\mathrm{z}^{*} \mathrm{y}\right), \mu(\mathrm{y} * \mathrm{x})\right\}$.

Putting $\mathrm{t}=\frac{1}{2}[\mu(\mathrm{z} * \mathrm{x})+\max \{\mu(\mathrm{z} * \mathrm{y}), \mu(\mathrm{y} * \mathrm{x})\}]$, then $\mu$

$(\mathrm{z} * \mathrm{x})>\mathrm{t}$ and

$0 \leq \max \{\mu(\mathrm{z} * \mathrm{y}), \mu(\mathrm{y} * \mathrm{x})\}<\mathrm{t} \leq 1$, hence

$\mu\left(\mathrm{z}^{*} \mathrm{y}\right)<\mathrm{t}$ and $\mu(\mathrm{y} * \mathrm{x})<\mathrm{t}$, which imply that

$(\mathrm{z} * \mathrm{y}) \in \mu_{\mathrm{t}}$ and $(\mathrm{y} * \mathrm{x}) \in \mu_{\mathrm{t}}$, since $\mu_{\mathrm{t}}$ is an anti-fuzzy

KUS-ideal, it follows that $(\mathrm{z} * \mathrm{x}) \in \mu_{\mathrm{t}}$ and that $\mu(\mathrm{z} * \mathrm{x}) \leq$

$\mathrm{t}$, this is also a contradiction. Hence $\mu$ is an anti-fuzzy KUSideal of $\mathrm{X}$. $\triangle$

Corollary 4.2. If a fuzzy subset $\mu$ of KUS-algebra $X$ is an anti-fuzzy KUS-ideal, then for every 
$\mathrm{t} \in \operatorname{Im}(\mu), \mu_{\mathrm{t}}$ is a KUS-ideal of X.

Remark 4.3. Let $\mu$ be an anti-fuzzy KUS-ideal of KUSalgebra $X$, then the KUS-ideal $\mu_{t}, t \in[0,1]$ are called level KUS-ideals of $\mu$.

Corollary 4.4. Let I be a KUS-ideal of a KUS-algebra X, then for any fixed number $t$ in an open interval $(0,1)$, there exist an anti-fuzzy KUS-ideal $\mu$ of $X$ such that $\mu_{t}=I$.

Proof: $\quad$ Define $\mu: X \rightarrow[0: 1]$ by

$\mu(x)=\left\{\begin{array}{cc}0, & \text { if } x \in I \\ t, & \text { if } x \notin I .\end{array}\right.$

Where $\mathrm{t}$ is a fixed number in $(0,1)$. Clearly, $\mu(0) \leq \mu(\mathrm{x})$ and we have one two level sets $\mu_{0}=\mathrm{I}, \mu_{\mathrm{t}}=\mathrm{X}$, which are KUS-ideals of $\mathrm{X}$, then from Theorem (4.1) $\mu$ is an anti-fuzzy KUS-ideal of X. $\Delta$

\section{Image and Pre-image of anti-fuzzy KUS- ideals}

Definition 5.1([2]). $f:(\mathrm{X} ; *, 0) \rightarrow\left(\mathrm{Y} ; *^{*}{ }^{`}, 0^{`}\right)$ be a mapping from a nonempty set $X$ to a nonempty set $Y$. If $\beta$ is a fuzzy subset of $X$, then the fuzzy subset $\mu$ of $Y$ defined by:

$\mathrm{f}(\mu)(\mathrm{y})=\beta(\mathrm{y})=\left\{\begin{array}{l}\inf _{\mathrm{xef}^{-1}(\mathrm{y})} \mu(\mathrm{x}) \\ 0 \quad \text { otherwise }\end{array} \quad\right.$ if $\mathrm{f}^{-1}(\mathrm{y})=\{\mathrm{x} \in \mathrm{X}, \mathrm{f}(\mathrm{x})=\mathrm{y}\} \neq \phi$

is said to be the image of $\mu$ under $f$.

Similarly if $\mu$ is a fuzzy subset of $\mathrm{Y}$, then the fuzzy subset $\mu=(\beta \circ f)$ in $\mathrm{X}$ (i.e., the fuzzy subset defined by $\mu$ $(\mathrm{x})=\beta(f(\mathrm{x}))$, for all $\mathrm{x} \in \mathrm{X})$ is called the pre-image of $\beta$ under $f$.

Theorem 5.2. An onto homomorphic pre-image of antifuzzy KUS-ideal is also an anti-fuzzy KUS-ideal.

Proof: Let $f:(\mathrm{X} ; *, 0) \rightarrow\left(\mathrm{Y} ; *^{*}{ }^{\prime}, 0^{\prime}\right)$ be an onto homomorphism of KUS-algebras,

$\beta$ is an anti-fuzzy KUS-ideal of Y and $\mu$ the pre-image of $\beta$ under $f$, then

$\beta(f(\mathrm{x}))=\mu(\mathrm{x})$, for all $\mathrm{x} \in \mathrm{X}$. Let $\mathrm{x} \in \mathrm{X}$, then

$\mu(0)=\beta(f(0))<\beta(f(\mathrm{x}))=\mu(\mathrm{x})$. Now let

$\mathrm{x}, \mathrm{y}, \mathrm{z} \in \mathrm{X}$, then

$$
\begin{aligned}
& \mu(\mathrm{z} * \mathrm{x})=\beta(f(\mathrm{z} * \mathrm{x}))=\beta\left(f(\mathrm{z}) *^{\prime} f(\mathrm{x})\right) \\
& \leq \max \left\{\beta\left(f(\mathrm{z}) *^{\prime} f(\mathrm{y})\right), \beta\left(f(\mathrm{y}) *^{\prime} f(\mathrm{x})\right)\right\} \\
& =\max \{\beta(f(\mathrm{z} * \mathrm{y})), \beta(f(\mathrm{y} * \mathrm{x}))\} \\
& =\max \{\mu(\mathrm{z} * \mathrm{y}), \mu(\mathrm{y} * \mathrm{x})\}, \text { and the proof is completed. }
\end{aligned}
$$

Definition 5.3. An anti fuzzy subset $\mu$ of $X$ has inf property if for any subset $T$ of $X$, there exist $t_{0} \in T$ such that $\mu(\mathrm{t})=\inf _{\mathrm{t} \in \mathrm{T}} \mu(\mathrm{t})$.

Theorem 5.4. Let $f:(\mathrm{X} ; *, 0) \rightarrow\left(\mathrm{Y} ; *^{\prime}, 0^{`}\right)$ be an onto homomorphism between KUS-algebras $\mathrm{X}$ and $\mathrm{Y}$ respectively . For every anti-fuzzy KUS-ideal $\mu$ in $\mathrm{X}, f(\mu)$ is an antifuzzy KUS-ideal of Y.

Proof: Let $\mathrm{y} \in \mathrm{Y}$, there exists $\mathrm{x} \in \mathrm{X}$ such that $\mathrm{f}(\mathrm{x})=\mathrm{y}$. Then $\mu(\mathrm{y})=\mu(\mathrm{f}(\mathrm{x})) \geq \mu(\mathrm{f}(0))=\mu\left(0^{\prime}\right)$.
Let $f: \mathrm{X} \rightarrow \mathrm{Y}$ be an onto homomorphism of KUSalgebras , $\mu$ is an anti-fuzzy KUS-ideal of $X$ with inf property and $\beta$ the image of $\mu$ under $f$, since $\mu$ is antifuzzy KUS-ideal of $X$, we have $\mu(0) \leq \mu(\mathrm{x})$ for all $\mathrm{x} \in \mathrm{X}$. Note that $0 \in f^{-1}\left(0^{\prime}\right)$, where 0 , $0^{\prime}$ are the zero of $\mathrm{X}$ and $\mathrm{Y}$, respectively. Thus $\beta\left(0^{\prime}\right)=$ $\inf _{t \in f^{-1}\left(x^{\prime}\right)} \mu(t)$

$=\beta\left(x^{\prime}\right)$, for all $x \in X$, which implies that

$\beta\left(0^{\prime}\right) \leq \inf _{t \in f^{-1}\left(x^{\prime}\right)} \mu(t)=\beta\left(x^{\prime}\right)$, for any $x^{\prime} \in Y$. Let $x^{\prime}, y^{\prime}, z^{\prime} \in$ $\mathrm{Y}$, then there exists $\mathrm{x}_{0}, \mathrm{y}_{0}, \mathrm{z}_{0} \in \mathrm{X}$ such that $\mathrm{x}_{0}=f^{-1}\left(\mathrm{x}^{\prime}\right), \mathrm{y}_{0}=$ $f^{-1}\left(\mathrm{y}^{\prime}\right), \mathrm{z}_{0}=f^{-1}\left(\mathrm{z}^{\prime}\right)$. It follows that $\mu\left(\mathrm{z}_{0} * \mathrm{y}_{0}\right)=\inf _{\mathrm{t} \in \mathrm{f}^{-1}\left(\mathrm{z}^{* *} \mathrm{y}^{\prime}\right)} \mu(\mathrm{t})$,

$\mu\left(\mathrm{y}_{0} * \mathrm{x}_{0}\right)=\inf _{\mathrm{t} \in \mathrm{f}^{-1}\left(\mathrm{y}^{* *} \mathrm{x}^{\prime}\right)} \mu(\mathrm{t})$ and

$\mu\left(\mathrm{z}_{0} * \mathrm{x}_{0}\right)=\inf _{\mathrm{t} \in \mathrm{f}^{-1}\left(\mathrm{z}^{*} \mathrm{x}^{\prime}\right)} \mu(\mathrm{t})$. Then

$f(\mu)\left(\mathrm{z}^{\prime} * \mathrm{x}^{\prime}\right)=\beta\left(\mathrm{z}^{\prime} * \mathrm{x}^{\prime}\right)=\inf _{\mathrm{t} \in \mathrm{f}^{-1}\left(\mathrm{z}^{* * \mathrm{x}^{\prime}}\right)} \mu(\mathrm{t})$

$=\mu\left(\mathrm{z}_{0} * \mathrm{x}_{0}\right) \leq \max \left\{\mu\left(\mathrm{z}_{0} * \mathrm{y}_{0}\right), \mu\left(\mathrm{y}_{0} * \mathrm{x}_{0}\right)\right\}$

$=\max \left[\inf _{t \in f^{-1}\left(z^{\prime *} y^{\prime}\right)} \mu(t), \inf _{t \in f^{-1}\left(y^{\prime *} x^{\prime}\right)} \mu(t)\right]$

$=\max \left\{\beta\left(\mathrm{z}^{\prime} * \mathrm{y}^{\prime}\right), \beta\left(\mathrm{y}^{\prime} * \mathrm{x}^{\prime}\right)\right\}$.

$=\max \left\{f(\mu)\left(\mathrm{z}^{\prime} * \mathrm{y}^{\prime}\right), f(\mu)\left(\mathrm{y}^{\prime} * \mathrm{x}^{\prime}\right)\right\}$.

Hence $f(\mu)$ is an anti-fuzzy KUS-ideal of Y. $\Delta$

\section{Cartesian product of anti-fuzzy KUS- ideals}

Definition 6.1 ([1]).A fuzzy relation $\mathrm{R}$ on any set $\mathrm{S}$ is a fuzzy subset R: $\mathrm{S} \times \mathrm{S} \rightarrow[0,1]$.

Definition 6.2 ([1]). If $\mathrm{R}$ is a fuzzy relation on sets $\mathrm{S}$ and $\beta$ is a fuzzy subset of $S$, then $R$ is a fuzzy relation on $\beta$ if $\mathrm{R}(\mathrm{x}, \mathrm{y}) \geq \max \{\beta(\mathrm{x}), \beta(\mathrm{y})\}$, for all $\mathrm{x}, \mathrm{y} \in \mathrm{S}$.

Definition 6.3([1]). Let $\mu$ and $\beta$ be fuzzy subsets of a set $\mathrm{S}$. The cartesian product of $\mu$ and $\beta$ is defined by $(\mu \times \beta)(x, y)=\max \{\mu(x), \beta(y)\}$, for all $x, y \in S$.

Lemma 6.4([1]). Let $S$ be a set and $\mu$ and $\beta$ be fuzzy subsets of $\mathrm{S}$. Then,

(1) $\mu \times \beta$ is a fuzzy relation on $S$,

(2) $(\mu \times \beta)_{t}=\mu_{t} \times \beta_{t}$, for all $t \in[0,1]$.

Definition 6.5([1]). Let $S$ be a set and $\beta$ be fuzzy subset of $S$. The strongest fuzzy relation on $S$, that is, a fuzzy relation on $\beta$ is $R_{\beta}$ given by

$\mathrm{R}_{\beta}(\mathrm{x}, \mathrm{y})=\max \{\beta(\mathrm{x}), \beta(\mathrm{y})\}$, for all $\mathrm{x}, \mathrm{y} \in \mathrm{S}$.

Lemma 6.6([1]). For a given fuzzy subset $\beta$ of a set $S$, let $R_{\beta}$ be the strongest fuzzy relation on $S$. Then for $t \in[0,1]$, we have $\left(R_{\beta}\right)_{t}=\beta_{t} \times \beta_{t}$.

Proposition 6.7. For a given fuzzy subset $\beta$ of a KUSalgebra $X$, let $R_{\beta}$ be the strongest fuzzy relation on $X$. If $\beta$ is an anti-fuzzy KUS-ideal of $\mathrm{X} \times \mathrm{X}$, then $R_{\beta}(x, x) \geq R_{\beta}(0,0)$, for all $x \in X$ 
Proof: Since $\mathrm{R}_{\beta}$ is a strongest fuzzy relation of $\mathrm{X} \times \mathrm{X}$, it follows from that,

$\mathrm{R}_{\beta}(\mathrm{x}, \mathrm{x})=\max \{\beta(\mathrm{x}), \beta(\mathrm{x})\} \geq \max \{\beta(0), \beta(0)\}$

$=\mathbf{R}_{\beta}(0,0)$, which implies that $\mathbf{R}_{\beta}(x, x) \geq \mathbf{R}_{\beta}(0,0)$. $\Delta$

Proposition 6.8. For a given fuzzy subset $\beta$ of a KUSalgebra $X$, let $R_{\beta}$ be the strongest fuzzy relation on $X$. If $R_{\beta}$ is an anti-fuzzy KUS-ideal of $X \times X$, then $\beta(x) \geq \beta(0)$, for all $\mathrm{x} \in \mathrm{X}$.

Proof: Since $R_{\beta}$ is an anti-fuzzy KUS-ideal of $X \times X$, it follows from (Akus 1 ), $R_{\beta}(x, x) \geq R_{\beta}(0,0)$, where $(0,0)$ is the zero element of

$\mathrm{X} \times \mathrm{X}$. But this means that $\max \{\beta(\mathrm{x}), \beta(\mathrm{x})\} \geq \max \{\beta(0)$, $\beta(0)\}$ which implies that $\beta(\mathrm{x}) \geq \beta(0)$. $\triangle$

Remark 6.9([1]). Let $\mathrm{X}$ and $\mathrm{Y}$ be KUS-algebras, we define (*) on $\mathrm{X} \times \mathrm{Y}$ by : for all $(\mathrm{x}, \mathrm{y}),(\mathrm{u}, \mathrm{v}) \in \mathrm{X} \times \mathrm{Y},(\mathrm{x}, \mathrm{y})$ $*(\mathrm{u}, \mathrm{v})=(\mathrm{x} * \mathrm{u}, \mathrm{y} * \mathrm{v})$. Then clearly $(\mathrm{X} \times \mathrm{Y} ; * .(0,0))$ is a KUS-algebra.

Theorem 6.10. Let $\mu$ and $\beta$ be an anti-fuzzy KUS-ideals of KUS-algebra $X$. Then $\mu \times \beta$ is an anti-fuzzy KUS-ideal of

$\mathrm{X} \times \mathrm{X}$.

Proof: Note first that for every $(\mathrm{x}, \mathrm{y}) \in \mathrm{X} \times \mathrm{X}$,

$(\mu \times \beta)(0,0)=\max \{\mu(0), \beta(0)\}$

$\leq \max \{\mu(\mathrm{x}), \beta(\mathrm{y})\}=(\mu \times \beta)(\mathrm{x}, \mathrm{y})$.

Now let $\left(\mathrm{x}_{1}, \mathrm{x}_{2}\right),\left(\mathrm{y}_{1}, \mathrm{y}_{2}\right),\left(\mathrm{z}_{1}, \mathrm{z}_{2}\right) \in \mathrm{X} \times \mathrm{X}$. Then

$(\mu \times \beta)\left(z_{1} * x_{1}, z_{2} * x_{2}\right)=\max \left\{\mu\left(z_{1} * x_{1}\right), \beta\left(z_{2} * x_{2}\right)\right\} \leq \max$

$\left\{\max \left\{\mu\left(\mathrm{z}_{1} * \mathrm{y}_{1}\right), \mu\left(\mathrm{y}_{1} * \mathrm{x}_{1}\right)\right\}\right.$, $\left.\max \left\{\beta\left(\mathrm{z}_{2} * \mathrm{y}_{2}\right), \beta\left(\mathrm{y}_{2} * \mathrm{x}_{2}\right)\right\}\right\}$

$=\max \left\{\max \left\{\mu\left(\mathrm{z}_{1} * \mathrm{y}_{1}\right), \beta\left(\mathrm{z}_{2} * \mathrm{y}_{2}\right)\right\}\right.$, $\left.\max \left\{\mu\left(\mathrm{y}_{1} * \mathrm{x}_{1}\right), \beta\left(\mathrm{y}_{2} * \mathrm{x}_{2}\right)\right\}\right\}$

$=\max \left\{(\mu \times \beta)\left(\mathrm{z}_{1} * \mathrm{y}_{1}, \mathrm{z}_{2} * \mathrm{y}_{2}\right)\right.$,

$$
\left.(\mu \times \beta)\left(\mathrm{y}_{1} * \mathrm{x}_{1}, \mathrm{y}_{2} * \mathrm{x}_{2}\right)\right\}
$$

Hence $(\mu \times \beta)$ is an anti-fuzzy KUS-ideal of $X \times X$. $\triangle$

Theorem 6.11. Let $\mu$ and $\beta$ be anti-fuzzy subsets of KUSalgebra $X$ such that $\mu \times \beta$ is an anti-fuzzy KUS-ideal of

$\mathrm{X} \times \mathrm{X}$. Then for all $\mathrm{x} \in \mathrm{X}$,

(i) either $\mu(0) \leq \mu(\mathrm{x})$ or $\beta(0) \leq \beta(\mathrm{x})$.

(ii) $\mu(0) \leq \mu(\mathrm{x})$, then either $\beta(0) \leq \beta$ (x) or $\beta(0) \leq \mu(\mathrm{x})$

(iii) If $\beta(0) \leq \beta$ (x), then either $\mu(0) \leq \mu$ (x) or $\beta(0) \leq \mu(x)$.

(iv) Either $\mu$ or $\beta$ is an anti-fuzzy KUS-ideal of $X$.

Proof.

(i) suppose that $\mu(0)>\mu(x)$ and $\beta(0)>\beta$ (y) for some $\mathrm{x}, \mathrm{y} \in \mathrm{X}$. Then $(\mu \times \beta)(\mathrm{x}, \mathrm{y})$

$=\max \{\mu(\mathrm{x}), \beta(\mathrm{y})\}<\max \{\mu(0), \beta(0)\}=(\mu \times \beta)(0,0)$. This is a contradiction and we obtain (i).

(ii) Assume that there exist $\mathrm{x}, \mathrm{y} \in \mathrm{X}$ such that

$\beta(0)>\mu(\mathrm{x})$ and $\beta(0)>\beta(y)$. Then $(\mu \times \beta)(0,0)=\max \{\mu$

$(0), \beta(0)\}=\beta(0)$ it follows that $\quad(\mu \times \beta)(\mathrm{x}, \mathrm{y})=\max \{\mu(\mathrm{x})$,

$\beta(\mathrm{y})\}<\beta(0)=(\mu \times \beta)(0,0)$ which is a contradiction. Hence (ii) holds.

(iii) is by similar method to part (ii).

(iv) Suppose $\beta(0) \leq \beta$ (x) by (i), then form (iii) either $\mu$ (0) $\leq \mu(\mathrm{x})$ or $\beta(0) \leq \mu(\mathrm{x})$ for all $\mathrm{x} \in \mathrm{X}$.
If $\mu(0) \leq \beta(x)$, for any $x \in X$, then $(\mu \times \beta)(0, x)=\max$ $\{\mu(0), \beta(\mathrm{x})\}=\beta(\mathrm{x})$. Let $\left(\mathrm{x}_{1}, \mathrm{x}_{2}\right),\left(\mathrm{y}_{1}, \mathrm{y}_{2}\right),\left(\mathrm{z}_{1}, \mathrm{z}_{2}\right) \in \mathrm{X} \times \mathrm{X}$, since $(\mu \times \beta)$ is an anti-fuzzy KUS-ideal of $X \times X$, we have $(\mu \times \beta)\left(\mathrm{z}_{1} * \mathrm{x}_{1}, \mathrm{z}_{2} * \mathrm{x}_{2}\right) \leq \max \left\{(\mu \times \beta)\left(\mathrm{z}_{1} * \mathrm{y}_{1}, \mathrm{z}_{2} * \mathrm{y}_{2}\right)\right.$,

$$
\left.(\mu \times \beta)\left(y_{1} * x_{1}, y_{2} * x_{2}\right)\right\}---(A)
$$

If we take $\mathrm{x}_{1}=\mathrm{y}_{1}=\mathrm{z}_{1}=0$, then

$\beta\left(\mathrm{z}_{2} * \mathrm{x}_{2}\right)=(\mu \times \beta)\left(0, \mathrm{z}_{2} * \mathrm{x}_{2}\right)$

$\leq \max \left\{(\mu \times \beta)\left(0, \mathrm{z}_{2} * \mathrm{y}_{2}\right),(\mu \times \beta)\left(0, \mathrm{y}_{2} * \mathrm{x}_{2}\right)\right\}$

$=\max \left\{\max \left\{\mu(0), \beta\left(\mathrm{z}_{2} * \mathrm{y}_{2}\right)\right\}\right.$, $\left.\max \left\{\mu(0), \beta\left(\mathrm{y}_{2} * \mathrm{x}_{2}\right)\right\}\right\}$

$=\max \left\{\beta\left(\mathrm{z}_{2} * \mathrm{y}_{2}\right), \beta\left(\mathrm{y}_{2} * \mathrm{x}_{2}\right)\right\}$

This prove that $\beta$ is an anti-fuzzy KUS-ideal of $X$.

Now we consider the case $\mu(0) \leq \mu(\mathrm{x})$ for all $\mathrm{x} \in \mathrm{X}$. Suppose that $\mu(0)>\mu(\mathrm{y})$ for some $\mathrm{y} \in \mathrm{X}$. then

$\beta(0) \leq \beta(y)<\mu(0)$.

Since $\mu(0) \leq \mu(\mathrm{x})$ for all $\mathrm{x} \in \mathrm{X}$, it follows that $\beta(0)<\mu$ (x) for any $x \in X$.

Hence $(\mu \times \beta)(x, 0)=\max \{\mu(x), \beta(0)\}=\mu(x)$ taking $x_{2}$ $=\mathrm{y}_{2}=\mathrm{z}_{2}=0$ in $(\mathrm{A})$, then

$\mu\left(\mathrm{z}_{1} * \mathrm{x}_{1}\right)=(\mu \times \beta)\left(\mathrm{z}_{1} * \mathrm{x}_{1}, 0\right)$

$\leq \max \left\{(\mu \times \beta)\left(\mathrm{z}_{1} * \mathrm{y}_{1}, 0\right),(\mu \times \beta)\left(\mathrm{y}_{1} * \mathrm{x}_{1}, 0\right)\right\}$

$=\max \left\{\max \left\{\mu\left(\mathrm{z}_{1} * \mathrm{y}_{1}\right), \beta(0)\right\}\right.$, $\left.\max \left\{\mu\left(\mathrm{y}_{1} * \mathrm{x}_{1}\right), \beta(0)\right\}\right\}$

$=\max \left\{\mu\left(\mathrm{z}_{1} * \mathrm{y}_{1}\right), \mu\left(\mathrm{y}_{1} * \mathrm{x}_{1}\right)\right\}$

Which proves that $\mu$ is an anti-fuzzy KUS-ideal of $X$.

Hence either $\mu$ or $\beta$ is an anti-fuzzy KUS-ideal of $X$. $\triangle$

Theorem 6.12. Let $\beta$ be a fuzzy subset of a KUS-algebra $X$ and let $R_{\beta}$ be the strongest fuzzy relation on $X$, then $\beta$ is an anti-fuzzy KUS-ideal of $X$ if and only if $R_{\beta}$ is an antifuzzy KUS-ideal of $\mathrm{X} \times \mathrm{X}$.

Proof: Assume that $\beta$ is an anti-fuzzy KUS-ideal of $X$. By proposition (6.7), we get,

$\mathrm{R}_{\beta}(0,0) \leq \mathrm{R}_{\beta}(\mathrm{x}, \mathrm{y})$, for any $(\mathrm{x}, \mathrm{y}) \in \mathrm{X} \times \mathrm{X}$.

Let $\left(\mathrm{x}_{1}, \mathrm{x}_{2}\right),\left(\mathrm{y}_{1}, \mathrm{y}_{2}\right),\left(\mathrm{z}_{1}, \mathrm{z}_{2}\right) \in \mathrm{X} \times \mathrm{X}$, we have from $\left(\right.$ Akus $\left._{2}\right)$ :

$$
\begin{aligned}
& \mathrm{R}_{\beta}\left(\mathrm{z}_{1} * \mathrm{x}_{1}, \mathrm{z}_{2} * \mathrm{x}_{2}\right)=\max \left\{\beta\left(\mathrm{z}_{1} * \mathrm{x}_{1}\right), \beta\left(\mathrm{z}_{2} * \mathrm{x}_{2}\right)\right\} \\
& \leq \max \left\{\max \left\{\beta\left(\mathrm{z}_{1} * \mathrm{y}_{1}\right), \beta\left(\mathrm{y}_{1} * \mathrm{x}_{1}\right)\right\},\right. \\
& \left.\quad \max \left\{\beta\left(\mathrm{z}_{2} * \mathrm{y}_{2}\right), \beta\left(\mathrm{y}_{2} * \mathrm{x}_{2}\right)\right\}\right\} \\
& =\max \left\{\max \left\{\beta\left(\mathrm{z}_{1} * \mathrm{y}_{1}\right), \beta\left(\mathrm{z}_{2} * \mathrm{y}_{2}\right)\right\},\right. \\
& \left.\quad \max \left\{\beta\left(\mathrm{y}_{1} * \mathrm{x}_{1}\right), \beta\left(\mathrm{y}_{2} * \mathrm{x}_{2}\right)\right\}\right\} \\
& =\max \left\{\mathrm{R}_{\beta}\left(\mathrm{z}_{1} * \mathrm{y}_{1}, \mathrm{z}_{2} * \mathrm{y}_{2}\right), \mathrm{R}_{\beta}\left(\mathrm{y}_{1} * \mathrm{x}_{1}, \mathrm{y}_{2} * \mathrm{x}_{2}\right)\right\}
\end{aligned}
$$

Hence $R_{\beta}$ is an anti-fuzzy KUS-ideal of $\mathrm{X} \times \mathrm{X}$.

Conversely, suppose that $R_{\beta}$ is an anti-fuzzy KUS-ideal of

$X \times X$, by proposition (6.8) $\beta(0) \leq \beta$ (x) for all $x \in X$, which prove $\left(\right.$ Akus $\left._{1}\right)$.

Now, let $\left(\mathrm{x}_{1}, \mathrm{x}_{2}\right),\left(\mathrm{y}_{1}, \mathrm{y}_{2}\right),\left(\mathrm{z}_{1}, \mathrm{z}_{2}\right) \in \mathrm{X} \times \mathrm{X}$. Then, $\max \left\{\beta\left(\mathrm{z}_{1} * \mathrm{x}_{1}\right), \beta\left(\mathrm{z}_{2} * \mathrm{x}_{2}\right)\right\}=\mathrm{R}_{\beta}\left(\mathrm{z}_{1} * \mathrm{x}_{1}, \mathrm{z}_{2} * \mathrm{x}_{2}\right)$

$\leq \max \left\{\mathrm{R}_{\beta}\left(\left(\mathrm{z}_{1}, \mathrm{z}_{2}\right) *\left(\mathrm{y}_{1}, \mathrm{y}_{2}\right)\right), \mathrm{R}_{\beta}\left(\left(\mathrm{y}_{1}, \mathrm{y}_{2}\right) *\left(\mathrm{x}_{1}, \mathrm{x}_{2}\right)\right)\right\}$

$=\max \left\{\mathrm{R}_{\beta}\left(\left(\mathrm{z}_{1} * \mathrm{y}_{1}\right),\left(\mathrm{z}_{2} * \mathrm{y}_{2}\right)\right)\right.$,

$$
\left.\mathrm{R}_{\beta}\left(\left(\mathrm{y}_{1} * \mathrm{x}_{1}\right),\left(\mathrm{y}_{2} * \mathrm{x}_{2}\right)\right)\right\}
$$

$=\max \left\{\max \left\{\beta\left(\mathrm{z}_{1} * \mathrm{y}_{1}\right), \beta\left(\mathrm{z}_{2} * \mathrm{y}_{2}\right)\right\}\right.$,

$\left.\max \left\{\beta\left(\mathrm{y}_{1} * \mathrm{x}_{1}\right), \beta\left(\mathrm{y}_{2} * \mathrm{x}_{2}\right)\right\}\right\}$

In particular if we take $x_{2}=y_{2}=z_{2}=0$, then

$\beta\left(\mathrm{z}_{1} * \mathrm{x}_{1}\right) \leq \max \left\{\beta\left(\mathrm{z}_{1} * \mathrm{y}_{1}\right), \beta\left(\mathrm{y}_{1} * \mathrm{x}_{1}\right)\right\}$. This proves $\left(\right.$ Akus $\left._{2}\right)$ and $\beta$ is an anti- fuzzy KUS-ideal of $X$. $\triangle$ 
Theorem 6.13. Let $\mu$ and $\beta$ be fuzzy subsets of a KUSalgebra $X$ such that $\mu \times \beta$ is an anti-fuzzy KUS-ideal of $X \times X$. Then $\mu$ or $\beta$ is an anti-fuzzy KUS-ideal of $X$.

Proof: By theorem (6.11(i)), without loss of generality we assume that $\mu(\mathrm{x}) \geq \mu(0)$ for all $\mathrm{x} \in \mathrm{X}$. From theorem (6.11(iii)), it follows that either

$\beta(0) \leq \beta(x)$ or $\beta(0) \leq \mu(x)$. If $\mu(x) \geq \beta(0)$ for all $x \in X$, then $(\mu \times \beta)(0, x)=\max \{\beta(0), \mu(x)\}=$

$\mu(\mathrm{x})$. Let $(\mathrm{x}, \mathrm{y}) \in \mathrm{X} \times \mathrm{X}$, since $\mu \times \beta$ is an anti-fuzzy

KUS-ideal of $X$. By proposition (6.7), we get, $(\mu \times \beta)(0,0)$

$\leq(\mu \times \beta)(\mathrm{x}, \mathrm{y})$.

Let $\left(\mathrm{x}_{1}, \mathrm{x}_{2}\right),\left(\mathrm{y}_{1}, \mathrm{y}_{2}\right),\left(\mathrm{z}_{1}, \mathrm{z}_{2}\right) \in \mathrm{X} \times \mathrm{X}$, we have from $\left(\right.$ Akus $\left._{2}\right)$ :

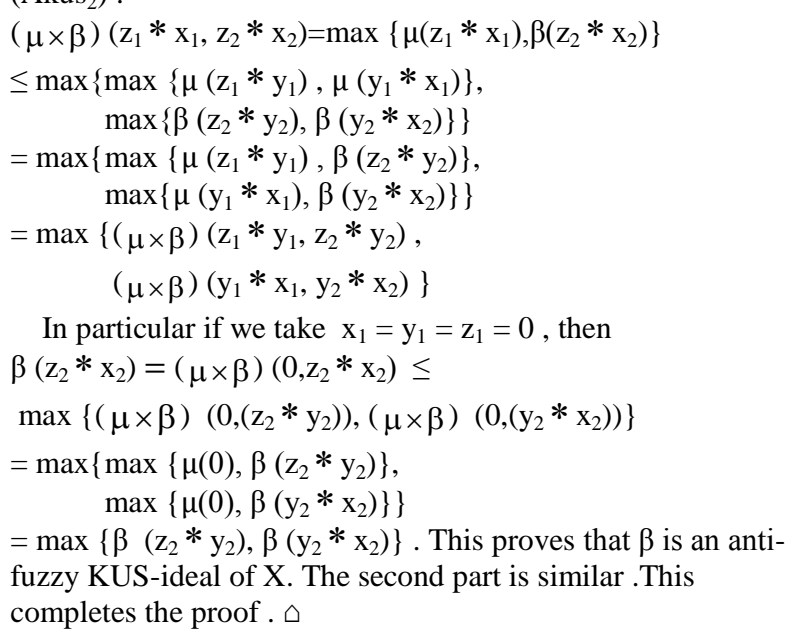

\section{ACKNOWLEDGMENTS}

Our thanks to Department of Pure Mathematics, Faculty of Sciences, Ain Shams University, Cairo, Egypt who have contributed towards development of the template .

\section{References}

[1] Bhattacharye P. and Mukheriee N.P., Fuzzy relations and fuzzy group, Inform Sci. ,vol. 36 (1985), 267-282 .

[2] Is'eki K. and Yanaka S., An introduction to theory of BCK-algebras, Math. Japonica, vol. 23 (1979), 1-20.

[3] Jun Y.B. , Hong S.M. and Roh E.H. , Fuzzy characteristic sub-algebras /ideals of a BCK-algebra, Pusan Kyongnam Math. J.(presently East Asian Math. J.), vol. 9 , no.1 (1993), 127-132.

[4] Kumbhojkar H.V. and Bapat M.S., Not-so-fuzzy fuzzy ideals, fuzzy sets and systems, vol.37 (1991), 237-243 .

[5] Meng J. and Jun Y.B., BCK-algebras, Kyung Moon Sa Co., Korea, 1994.

[6] Mostafa S.M., Abd-Elnaby M.A., Abdel-Halim F. and Hameed A.T., Fuzzy KUS-Ideals of KUS-Algebras, Submitted.

[7] Palaniappan N. and Arjunan K., The homomorphism ,anti homomorphism of a fuzzy and an anti fuzzy ideals , Varahmihir Journal of Math. Sciences, vol.6, no.1 (2006), 181-188.

[8] Prabpayak C. and Leerawat U., On isomorphisms of KU-algebras, Scientia Magna J., vol. 5 , no.3 (2009), 25 31.

[9] Prabpayak C. and Leerawat U., On ideals and congurences in KU-algebras, Scientia Magna J. , vol. 5 , no.1 (2009), 54-57.

[10] Zadeh L.A., Fuzzy sets, Inform. Control,vol.8 (1965), 338-353. 